\title{
CHILD MALTREATMENT IN TURKEY: COMPARISON OF PARENT AND CHILD REPORTS
}

\author{
Zeynep Sofuoğlu', Görkem Sarıyer², M. Gökalp Ataman ${ }^{3}$ \\ ${ }^{1}$ Association of Emergency Ambulance Physicians, Izmir, Turkey \\ ${ }^{2}$ Faculty of Economics and Administrative Sciences, Yasar University, Izmir, Turkey \\ ${ }^{3}$ Department of Emergency, Çiğli Research and Training Hospital, Izmir, Turkey
}

\section{SUMMARY}

Background and Aim: Child maltreatment, i.e. abuse and neglect, is a significant problem worldwide and can cause impaired physical and mental health throughout life. The true extent still remains unknown in all countries, including Turkey. The aim of this study was to apply the two versions of the International Society for the Prevention of Child Abuse and Neglect (ISPCAN) Child Abuse Screening Tool of ICAST-C and ICAST-P, which are used to assess child and parent feedback and to compare reports given by children and those given by parents. This is the first study of its kind conducted in Turkey.

Methods: First, ICAST was translated into Turkish by bilingual experts. Students and their parents were asked to complete ICAST-C and ICAST-P respectively, with the help of trained researchers. In total, data from 2,608 matched reports (2,608 children and 2,608 parents) was obtained. Descriptive statistics were used to evaluate demographical variables, and chi-square tests were employed to investigate the statistical significance of comparisons.

Results: The present study demonstrated that Turkish parents consider rebukes, insults and corporal punishment effective ways of disciplining children. According to parents' reports, the use of psychological abuse was most prevalent against boys aged 16 , while the use of physical abuse was most prevalent against boys aged 13 . A statistically significant relationship was found between parents' economic conditions and child abuse $(p<0.01)$. No significant relationship was detected between maternal educational levels and child abuse $(p>0.05)$. However, the relationship between paternal educational background and psychological abuse was observed to be significant $(p<0.05)$. A comparison of children's and parents' reports shows that parents tended to under-report child maltreatment.

Conclusions: The results show that there is a significant healthcare problem in Turkey, since child maltreatment is prevalent, but parents are not generally aware of its extent. Possible approaches to changing this situation include efforts to increase education levels, promoting public awareness, and strengthening political commitments.

Key words: child abuse and neglect, child maltreatment, ICAST-C, ICAST-P, parental reports, public health

Address for correspondence: G. Sarıyer, Faculty of Economics and Administrative Sciences, Yasar University, Bornova, Izmir, Turkey. E-mail: gorkem.ataman@yasar.edu.tr

http://dx.doi.org/10.21101/cejph.a4155

\section{INTRODUCTION}

Child abuse and neglect (CAN) is a major public health and social welfare problem around the world (1). According to the World Health Organization (WHO) reports, CAN is a very common worldwide phenomenon, yet also one of the most unrecognized and under-researched (2). Various case definitions exist for various types of CAN. Giovannoni defined abuse as acts of omission that result in harm, and defined neglect as acts of omission that have negative effects (3). According to Gilbert et al. physical abuse is the intentional use of force or implementations against a child that results in, or has the potential to result in, physical injury; psychological (emotional) abuse is an intentional behaviour that conveys to a child that he/she is worthless, flawed, unloved, unwanted, endangered, or valued only in meeting another's needs; and neglect is the failure to meet a child's basic physical, emotional, medical, or educational needs, the failure to provide adequate nutrition, hygiene, shelter, or the failure to ensure a child's safety (4).
Different screening tools are used to explore the prevalence of CAN in different countries (5-8). In order to address deficiencies in previous screening tools due to cross-cultural, multicultural and multinational differences, the International Society for the Prevention of Child Abuse and Neglect (ISPCAN) developed Child Abuse Screening Tool instruments. The two versions of International Child Abuse Screening tools (ICAST) are known as ICAST-C and ICAST-P. The former is multinational, multilingual, and consensus-based instrument designed to measure the prevalence of child victimization (9), while the latter is a similar instrument which measures the prevalence of abusive parental behaviour towards children (10). Although widely used to measure CAN data in the US, European countries and other countries in both East and West, these tools have only recently been recognized in Turkey. A Turkish study measuring the negative childhood experiences using the ICAST-C screening tool showed that Turkey is confronted with a very significant health problem, which also presents a potential risk to adults (11). 
However, relying on the responses of either the child or the parent alone might affect the reliability of the results (12). Parent reports of child maltreatment may involve response bias and provide significant underestimates $(13,14)$. Therefore, in order to determine the prevalence of CAN, child responses are considered as more accurate (15-17). However, the use of child reports without comparison with adult reports may also be problematic, since abused and neglected children tend to underreport the abuse or neglect experienced because they feel a sense of loyalty to parent (18-20). Thus, some studies in the child maltreatment literature found substantial differences between child and parent reports (21), while others revealed moderate agreement levels (22). Considering these concerns about the reliability of reports from a single information source (either child or parent), this study aims to achieve a more balanced view comparing data from both groups in order to examine the consistency of responses. This involves applying the ICAST-P tool in Turkey for the first time.

\section{MATERIALS AND METHODS}

\section{Sample}

The present study gathered data from three populous provinces: Izmir, Denizli and Zonguldak, representing western, central and northern regions of Turkey, respectively. The questionnaires were distributed to 5 th, 7 th and 10th grade students, with the respective ages of 11, 13 and 16, representing the (late) childhood, pre-adolescent and adolescent stages of life. Target schools for this study were identified by using "Random Number Generator" software, which ensures that a random sample set was generated.

In total, 5,125 students (2,415 from Izmir, 1,403 from Zonguldak and 1,307 from Denizli) responded to this study, while only 2,642 parents (1,380 from Izmir, 735 from Zonguldak and 527 from Denizli) participated. After the elimination of partially filled, mismatching (in terms of child and parent details), and child questionnaires without corresponding parent versions, the total number of paired questionnaires was determined to be 2,608 (1,357 from Izmir, 727 from Zonguldak and 524 from Denizli).

\section{Survey Instruments}

ICAST-C and ICAST-P were used as data collection tools for children and parents, respectively. In the context of this study, survey questions were translated into Turkish using scale retranslation, and adapted to the Turkish sample.

5 th graders were given the shorter version of ICAST-C questionnaire form, and 7th and 10th graders, the longer version. The short version included 37 questions in total, 17 about psychological abuse, 15 about physical abuse and 5 about positive parenting, while the longer version included 42 questions, consisting of 19 , 16 and 7 questions about the aforesaid issues, respectively. Parents were given the ICAST-P questionnaire form, with 40 questions (17 about psychological abuse, 16 about physical abuse and 7 about positive parenting).

These survey instruments include questions about sexual abuse, but these were eliminated from the current study due to legal and ethical restrictions.

\section{Design}

This study was designed as the Turkish contribution to the Balkan Epidemiological Study on Child Abuse and Neglect (BECAN). BECAN was established with the aim to prevent child abuse and neglect through the development of systematic research, promoting collaboration among public and private institutions and increasing public awareness. This approach was based on that of the Japanese Society for Prevention of Child Abuse and Neglect, JaSPCAN (23). After agreement among the nine Balkan states, i.e., Greece, Turkey, Bosnia-Herzegovina, Albania, Bulgaria, Romania, Macedonia, Croatia, and Serbia, BECAN became eligible for funding under the European Union Seventh Framework Programme.

In the first phase of this study, bilingual experts translated the English version of ICAST-C and ICAST-P tools into Turkish, and the terminology was reviewed by an expert in child maltreatment. It was decided to exclude some survey questions for cultural and legal reason.

In the second phase, the research team underwent field research training. This training covered issues such as gaining familiarity with the basic terminology in respect of CAN, the impacts of neglect on children, the applicable legislation, the ethical dimension of the study, the importance of confidentiality, the principle of non-harming, and the actions that should and should not be taken in the event of severe cases of CAN.

In the third phase, appointments were made with randomly chosen target schools. At the appointed time, the students completed the ICAST-C tool under the supervision of trained researchers. The questionnaire forms were coded without recording the identity of the student, but it was ensured that each child survey code was linked to the corresponding parent survey, ICAST-P. Children were also given the parent forms to deliver to their parents. The researchers collected the delivered child and parent surveys and matched them using the codes.

\section{Statistical Analysis}

SPSS 16.0 was used for statistical analysis. Descriptive statistics were calculated for demographic characteristics. Chi-squared tests were used to examine the levels of agreement between the matched child and parents reports according to the different types of child maltreatment.

\section{RESULTS}

The parent response rate was only $51.88 \%$ of the child rate. A total of 2,608 matched surveys were obtained, and the response rates for Izmir, Zonguldak and Denizli were 52.03\%, 27.88\% and $20.09 \%$, respectively. Thus, the response rate was the highest in the western region, which included Izmir, one of the most developed cities of Turkey.

\section{Demographic Information}

The following section gives the demographic distribution for the respondents of the 2,608 paired child-parent surveys. $57.09 \%$ of children were female, the age distribution is presented in Table 1. The average age of parents was 39.55 years, ranging between 
Table 1. Paired students - distribution by age and sex $(N=2,608)$

\begin{tabular}{|l|c|c|c|c|c|c|c|c|}
\hline Gender & 5th grade & $\%$ & 7 th grade & $\%$ & 10th grade & $\%$ & Total & $\%$ \\
\hline Girls & 446 & 30.00 & 379 & 25.40 & 664 & 44.60 & 1,489 & 57.00 \\
\hline Boys & 362 & 32.35 & 317 & 28.33 & 440 & 39.32 & 1,119 & 43.00 \\
\hline
\end{tabular}

18-60. $72.03 \%$ were mothers and $25.37 \%$ were fathers, as presented in Table 2. The educational status of caregivers was as follows: $59.70 \%$ of mothers and $42.07 \%$ of fathers had achieved a primary level of education or below, and only $6.97 \%$ of mothers and $12.42 \%$ of fathers had completed university or tertiary education, as shown in Table 3.

Parents' Opinions Regarding Corporal Punishment

When parents were asked about their opinions regarding prevalence of corporal punishment in Turkey generally, 9.46\% responded that there was almost none, $52.84 \%$ that there was some (i.e. it was practiced in $50 \%$ or fewer of families) and $37.70 \%$ that

Table 2. Relationship level of parents and caregivers with children $(N=2,608)$

\begin{tabular}{|l|c|c|}
\hline & $\mathbf{n}$ & $\%$ \\
\hline Mother & 1,863 & 72.03 \\
\hline Father & 656 & 25.37 \\
\hline Stepmother & 3 & 0.12 \\
\hline Stepfather & 1 & 0.04 \\
\hline Foster parent & 1 & 0.04 \\
\hline Sister & 23 & 0.89 \\
\hline Brother & 10 & 0.39 \\
\hline Grandmother & 12 & 0.46 \\
\hline Grandfather & 8 & 0.31 \\
\hline Aunt & 7 & 0.27 \\
\hline Uncle & 2 & 0.08 \\
\hline Total & 2,586 & 100.00 \\
\hline Did not respond & 22 & \\
\hline
\end{tabular}

Table 3. Parental educational status $(N=2,608)$

\begin{tabular}{|c|c|c|c|c|}
\hline \multirow{2}{*}{ Educational Status } & \multicolumn{2}{|c|}{ Mother $(\mathrm{N}=2,315)$} & \multicolumn{2}{|c|}{ Father $(\mathrm{N}=1,940)$} \\
\hline & $\mathrm{n}$ & $\%$ & $\mathrm{n}$ & $\%$ \\
\hline None & 77 & 3.33 & 12 & 0.62 \\
\hline Some years in primary school & 92 & 3.97 & 55 & 2.84 \\
\hline Primary school & 1,213 & 52.40 & 749 & 38.61 \\
\hline Middle school & 317 & 13.69 & 410 & 21.13 \\
\hline High school & 425 & 18.36 & 428 & 22.06 \\
\hline Vocational high school & 29 & 1.25 & 45 & 2.32 \\
\hline University & 141 & 6.09 & 218 & 11.24 \\
\hline Graduate School & 21 & 0.91 & 23 & 1.18 \\
\hline Total & 2,315 & 100.00 & 1,940 & 100.00 \\
\hline Motherless/fatherless & 115 & & 374 & \\
\hline Did not respond & 178 & & 294 & \\
\hline
\end{tabular}

it was common (i.e. it was practiced in more than $50 \%$ of families). When asked about the prevalence among their own family almost none), $15.18 \%$ as occasional or some and $5.15 \%$ as frequent or common. The complete data from the report is given in Table 4. When these values were investigated, it was observed that parents reported lower frequencies of punishment in families with closer relationships between family members, friends and neighbours, while the frequencies sharply increased with the lower relationship levels to parents, as to their city, province, and country.

\section{Parent Feedbacks Regarding Psychological, Physical Abuse, Positive Parenting}

Similar rates of psychological abuse were admitted by parents for boys and girls: $72.65 \%$ and $71.26 \%$, respectively. Among the age groups, it was seen that 10 th grade students, aged 16 , were the most subjected to psychological abuse, with the rate of $74.55 \%$, while the rates for the 7 th and 5 th graders were $73.42 \%$ and $66.83 \%$, respectively. The Chi-square test between groups showed that the likelihood of being subjected to psychological abuse depended on age and gender $(p<0.05, p<0.05)$.

Perception of the prevalence of physical abuse was also assessed. The physical abuse rates reported by parents show that boys were exposed to a higher level of abuse when compared to girls (45.85\% vs. $37.95 \%$ ). Rates of physical abuse were observed to be more prevalent among 7 th graders, with $44.68 \%$, compared to 5 th graders, with $43.94 \%$, and 10 th graders, with $37.32 \%$. Statistical analysis also showed that exposure to physical abuse is affected by the child's age and gender $(\mathrm{p}<0.05, \mathrm{p}<0.01)$.

Parents' feedback regarding positive parenting was extremely optimistic. More than $92.50 \%$ reported taking a positive approach to their children regardless of age and gender. Thus, no statistical difference between age and gender groups was observed in this area. members, $79.67 \%$ of parents responded as very infrequent (none or 
Table 4. Parents' opinions regarding corporal punishment $(N=2,608)$

\begin{tabular}{|c|c|c|c|c|c|c|c|}
\hline Region & $\begin{array}{c}\text { Almost } \\
\text { none/none }\end{array}$ & $\begin{array}{c}\text { Less than } \\
\text { a half }\end{array}$ & Almost a half & $\begin{array}{c}\text { More than } \\
\text { a half }\end{array}$ & Almost all & Total & $\begin{array}{l}\text { Did not } \\
\text { respond }\end{array}$ \\
\hline In your country? & 220 & 570 & 659 & 690 & 187 & 2,326 & 282 \\
\hline In your province? & 314 & 909 & 551 & 311 & 78 & 2,163 & 445 \\
\hline In your city/village? & 470 & 869 & 407 & 256 & 85 & 2,087 & 521 \\
\hline Among your neighbours? & 1,108 & 653 & 176 & 140 & 84 & 2,161 & 447 \\
\hline Among your friends? & 1,375 & 495 & 130 & 80 & 65 & 2,145 & 463 \\
\hline Among your family members? & 1,732 & 246 & 84 & 57 & 55 & 2,174 & 434 \\
\hline
\end{tabular}

Full details of the parent reports on psychological and physical abuse, and positive parenting are given in Table 5 .

\section{Comparison of Children and Parents' Feedback}

Table 6 shows the various findings of the comparisons between child and parent responses to different items of the instrument. For each item, parents tended to underestimate their negative behaviours and overestimate the positive ones. A significant difference was observed between the responses of children and parents to each item $(\mathrm{p}<0.01, \mathrm{p}<0.05)$.

\section{Relationship between Risk, Demographic Factors and Abuse Type}

Past research has provided evidence that children experiencing abusive parenting are more likely to become abusive parents themselves (24-27). Parental cognitions are also considered as significant aetiological factors in $\operatorname{CAN}(28,29)$. In addition, various socioeconomic factors may contribute to child abuse (30-33). In this part, the relationship between socioeconomic factors and child abuse were explored. Similar to past research, a statistically significant relationship was observed between exposure to physical

Table 5. Parents' feedback regarding abuse and positive parenting $(N=2,608)$

\begin{tabular}{|c|c|c|c|c|c|c|c|c|c|c|}
\hline & & \multicolumn{3}{|c|}{ Psychological Abuse } & \multicolumn{3}{|c|}{ Physical Abuse } & \multicolumn{3}{|c|}{ Positive Parenting } \\
\hline & & $\mathrm{n}$ & $\%$ & $x^{2}$ & $\mathrm{n}$ & $\%$ & $x^{2}$ & $\mathrm{n}$ & $\%$ & $x^{2}$ \\
\hline \multirow{2}{*}{ Gender } & Girl & 1,061 & 71.25 & \multirow{2}{*}{$6.40^{*}$} & 565 & 37.94 & \multirow{2}{*}{$16.44^{* *}$} & 1,407 & 94.5 & \multirow{2}{*}{1.11} \\
\hline & Boy & 813 & 72.65 & & 513 & 45.84 & & 1,062 & 94.9 & \\
\hline \multirow{3}{*}{ Age (years) } & 11 & 540 & 66.83 & \multirow{3}{*}{$18.01^{*}$} & 355 & 43.93 & \multirow{3}{*}{$13.24^{*}$} & 751 & 92.94 & \multirow{3}{*}{12.36} \\
\hline & 13 & 511 & 73.42 & & 311 & 44.68 & & 666 & 95.69 & \\
\hline & 16 & 823 & 76.25 & & 412 & 36.29 & & 1,052 & 96.72 & \\
\hline
\end{tabular}

${ }^{*} p<0.05,{ }^{* *} p<0.01$

Table 6. Differences in findings in comparisons of the parent and child surveys $(N=2,608)$

\begin{tabular}{|c|c|c|c|c|c|c|c|}
\hline \multirow{2}{*}{ Abuse type } & \multirow{2}{*}{ Item } & \multicolumn{3}{|c|}{ Parents' survey } & \multicolumn{3}{|c|}{ Children's survey } \\
\hline & & No & Yes & Did not respond & No & Yes & Did not respond \\
\hline \multirow[t]{7}{*}{ Psychological abuse } & I & 1,967 & 526 & 115 & 1,829 & 691 & 88 \\
\hline & $\|$ & 2,260 & 234 & 114 & 2,154 & 376 & 78 \\
\hline & III & 2,260 & 230 & 118 & 2,262 & 265 & 81 \\
\hline & IV & 2,442 & 54 & 112 & 2,493 & 77 & 38 \\
\hline & V & 2,438 & 100 & 70 & 2,474 & 111 & 23 \\
\hline & $\mathrm{VI}$ & 2,433 & 48 & 127 & 2,516 & 60 & 32 \\
\hline & VII & 2,405 & 101 & 102 & 2,459 & 104 & 45 \\
\hline \multirow[t]{2}{*}{ Physical abuse } & VIII & 2,453 & 75 & 80 & 2,456 & 123 & 29 \\
\hline & IX & 2,433 & 52 & 123 & 2,502 & 65 & 41 \\
\hline Positive parenting & $x$ & 2,260 & 235 & 113 & 2,240 & 298 & 70 \\
\hline
\end{tabular}

Item-l: Have you ever compared your child to other children in such a manner that leads to self-abasement?

Item-II: Have your ever knowingly put your child to shame in order to ensure that he/she feels uncomfortable or humiliated?

Item-III: Have you ever said "I wish you had never been born!" ?

Item-IV: Have you ever abstained from taking him/her home?

Item-V: Have you ever frightened your child by threatening to summon a spirit, ghost or any other supernatural force?

Item-VI: Have you ever gone so far to tell him/her that you would kill him/her?

Item-VII: Have you ever locked your child in a dark or small room?

Item-VIII: Have you ever forced hot pepper into your child's mouth to make him/her suffer?

Item-IX: Have you ever forced your child to kneel down or to remain standing to make him/her suffer?

Item-X: Have you ever deprived your child of his/her money or rights? 
abuse in childhood and the tendency to engage in physical abuse of children as a parent, while a similar relation was observed between the exposure to psychological abuse and the tendency to apply it as an adult $(\mathrm{p}<0.01)$. The parents who considered beating as an effective method of discipline were naturally those who tended to be physically abusive parents $(\mathrm{p}<0.01)$. Economic conditions were significantly related to both physical and psychological abuse $(p<0.01)$. No clear relationship was observed between the mother's educational background and different abuse types; in contrast, there seems to be a significant relationship $(p<0.05)$ between the father's educational background and psychological abuse. These results are shown in detail in Table 7.

\section{DISCUSSION}

The current study shows that many findings in the child maltreatment literature are valid in the case of Turkey; for example, children were more likely than parents to report CAN, and parents' abusive approaches differed according to the age and gender of the child. Furthermore, there was a relationship between exposure to abusive parenting as a child, and practicing abusive parenting as an adult. Parental cognitions and socioeconomic factors were seemingly significantly related to child maltreatment.

In the current study, children were much more responsive compared to parents; 5,125 students compared to only 2,642 parents agreed to participate in the survey. Izmir, as the most developed region among the three, showed a higher response rate. The demographic analysis showed that the educational backgrounds of parents were generally low.

Similar to a study using data from a larger, nationally more representative sample, in this study, it was observed that males were more likely than females to have experienced physical abuse during childhood (34). This result was also obtained for psychological abuse. These observations can be interpreted as follows: harsher discipline for male children and adolescents can be partially explained by the deeply-rooted traditions of patriarchy of Eastern countries. Regarding age, it was observed that physical abuse is most prevalent at the 7 th grade, i.e. at the age of 13 , when young people are not considered to have reached adulthood. In contrast, psychological abuse was observed more prevalent at the age of 16 , the age of adolescence at which physical abuse is considered less appropriate. In regard to positive parenting, no statistical difference was observed based on age or gender groups; thus, parents reported a positive approach to all children.

When the child and parent reports were compared, it was observed that parents tended to underreport CAN, and overreport positive parenting behaviours, as discussed in the past studies (13, 14). This observation shows that parents tend to either be unaware of, or deliberately underestimate their abusive behaviours. The values given in Table 4 additionally show that parents accept the prevalence of CAN in Turkey generally, and even in their own city, but strongly believe that the frequency of CAN is decreasing within their immediate community, i.e. among their neighbours, friends and family members. The numbers for each of the items in Table 6 similarly shows that parents tend to overreport their positive behaviours while underreporting the negative ones.

Different studies have shown that parents who experienced abusive behaviour in childhood apply harsher methods discipline as adults $(8,24-27)$. The present study showed that this tendency applies in Turkey, those abused in childhood are more likely to become abusive parents themselves. Parents' economic conditions seem to be highly related to abusive behaviour. Thus, parents facing the challenges of surviving on low incomes are more likely to maltreat their children compared to those on higher incomes. An interesting result of this study is the absence of any relation between abusive behaviour and mother's educational background, suggesting that in Turkey, levels of maltreatment of children by mothers do not vary according to their educational level. In demographic analysis, it was reported that $72.03 \%$ of the parental respondents were mothers, showing the importance of the role of mother in a child's development. These results collectively show a potential risk for the future generation, since maltreatment received in childhood can greatly influence long-term wellbeing (35-37). In addition, the education level of fathers was observed to be significantly related with the tendency to practice psychological abuse, showing the key role of education in determining a father's likelihood to engage in abuse.

\section{CONCLUSION}

This study is important as the first effort in Turkey to collectively and comparatively apply ICAST-C and ICAST-P, multinational, multilingual and consensus-based instruments, which allow a realistic estimation of child victimization levels. Thus, the results provide data which can be compared to corresponding data from other countries.

Table 7. Relationship between risk and demographic factors and abuse type

\begin{tabular}{|l|c|c|c|}
\hline Factors & Abuse type & $\chi^{2}$ & p value \\
\hline Parent being exposed to violence by their own parents & Physical abuse & 0.203 & $<0.01$ \\
\hline Parent being exposed to snub/insult by their own parents & Psychological abuse & 0.179 & $<0.01$ \\
\hline Parent being of the opinion that beating is an effective method to discipline child & Physical abuse & 0.160 & $<0.01$ \\
\hline Economic conditions & Physical abuse & -0.061 & $<0.01$ \\
\hline Economic conditions & Psychological abuse & -0.083 & $<0.01$ \\
\hline Mother's educational background & Psychological abuse & -0.017 & $>0.05$ \\
\hline Mother's educational background & Physical abuse & -0.018 & $>0.05$ \\
\hline Father's educational background & Psychological abuse & 0.076 & $<0.05$ \\
\hline Father's educational background & Physical abuse & 0.020 & $>0.05$ \\
\hline
\end{tabular}


An important outcome of the current work is the realization that Turkey is confronted with a significant public healthcare problem, since parents are either unaware of, or tend to deny the true extent of the prevalence of child maltreatment. The generally low levels of education attainment and harsh cultural impositions make the situation even more serious. Since the current generation will determine the future of Turkey, it is necessary to take action to prevent potential negative consequences of this trend. Achieving this goal will involve making efforts to increase educational levels, the promotion of public awareness and the strengthening of political commitments.

\section{Acknowledgements}

The authors would like to thank Prof. Dr. Resmiye Oral for her invaluable support throughout this research project.

The Balkan Epidemiological Study on Child Abuse and Neglect (BECAN) was conducted within the EU 7th Framework Programme - BECAN EU 7th FW GA NO: 223478

\section{Ethics Committee Approval}

Ethics committee approval was received from the Ethics Committee of Izmir Tepecik Education and Research Hospital Chief Physician Office Local Ethics Committee (29.11.2011-29).

\section{Conflict of Interests}

None declared

\section{REFERENCES}

1. Rao S, Lux AL. The epidemiology of child maltreatment. Paediatr Child Health. 2012;22(11):459-64.

2. World Health Organization; International Society for the Prevention of Child Abuse and Neglect. 2006. Preventing child maltreatment: a guide to taking action and generating evidence. Geneva: WHO; 2006.

3. Giovannoni JM. Parental mistreatment: perpetrators and victims. J Marriage Fam. 1971;33(4):649-57.

4. Gilbert R, Widom CS, Browne K, Fergusson D, Webb E, Janson S. Burden and consequences of child maltreatment in high-income countries. Lancet. 2009 Jan 3;373(9657):68-81.

5. Brown J, Cohen P, Johnson JG, Salzinger S. A longitudinal analysis of risk factors for child maltreatment: findings of a 17-year prospective study of officially recorded and self-reported child abuse and neglect. Child Abuse Negl. 1998 Nov;22(11):1065-78.

6. Fernandopulle S, Fernando D. Development and initial validation of a scale to measure emotional abuse among school children aged 13-15 years in Sri Lanka. Child Abuse Negl. 2003 Oct;27(10):1087-99.

7. Stowman SA, Donohue B. Assessing child neglect: a review of standardized measures. Aggress Violent Behav. 2005;10(4):491-512.

8. Acehan S, Bilen A, Ay MO, Gülen M, Avcı A, Icme F. Evaluation of child abuse and neglect. Arch Med Rev J. 2013;22(4):591-614.

9. Zolotor AJ, Runyan DK, Dunne MP, Jain D, Péturs HR, Ramirez C, et al. ISPCAN Child Abuse Screening Tool Children's Version (ICAST-C): Instrument development and multi-national pilot testing. Child Abuse Negl. 2009 Nov;33(11):833-41.

10. Runyan DK, Dunne MP, Zolotor AJ, Madrid B, Jain D, Gerbaka B, et al. The development and piloting of the ISPCAN Child Abuse Screening ToolParent version (ICAST-P). Child Abuse Negl. 2009 Nov;33(11):826-32.

11. Sofuoğlu Z, Oral R, Aydın F, Cankardeş S, Kandemirci B, Koç F, et al. Epidemiological study of negative childhood experiences in three provinces of Turkey. Turk Pediatri Ars. 2014 Mar 1;49(1):47-56.

12. Fantuzzo JW, Lindquist CU. The effects of observing conjugal violence on children: a review of research methodology. J Fam Violence. 1989;4(1):77-94.

13. Kaufman KL, Hilliker DR, Lahtrop P, Daleiden EL. Assessing child sexual offenders' modus operandi: accuracy in self-reported use of threats and coercion. Sex Abuse.1993;6(3):213-29.
14. Kolko DJ, Kazdin AE, Day BT. Children's perspective in the assessment of family violence: psychometric characteristics and comparison to parent reports. Child Maltreat. 1996;1(2):156-67.

15. Richters JE, Martinez P. The NIMH community violence project: I. Children as victims of and witnesses to violence. Psychiatry. 1993 Feb;56(1):7-21.

16. Winegar RK, Lipschitz DS. Agreement between hospitalized adolescents' self-reports of maltreatment and witnessed home violence and clinician reports and medical records. Compr Psychiatry. 1999 Sep-Oct;40(5):347-52.

17. McGee RA, Wolfe DA, Wilson SK. Multiple maltreatment experiences and adolescent behavior problems: adolescents' perspectives. Dev Psychopathol. 1997 Winter;9(1):131-49.

18. Jouriles EN, Mehta P, McDonald R, Francis DJ. Psychometric properties of family members' reports of parental physical aggression toward clinic-referred children. J Consult Clin Psychol. 1997 Apr;65(2):309-18.

19. McGee RA, Wolfe DA, Yuen SA, Wilson SK, Carnochan J. The measurement of maltreatment: a comparison of approaches. Child Abuse Negl. $1995 \mathrm{Feb} ; 19(2): 233-49$.

20. Jaffe PG, Sudermann M, Reitzel D. Child witnesses of marital violence. In: Ammerman RT, Hersen M, editors. Assessment of family violence: a clinical and legal sourcebook. New York: Wiley; 1992. p. 313-31.

21. Chan KL. Comparison of parent and child reports on child maltreatment in a representative household sample in Hong Kong. J Fam Violence. 2012 Jan;27(1):11-21.

22. Jouriles EN, Norwood WD. Physical aggression toward boys and girls in families characterized by the battering of women. J Fam Psychol. 1995;9(1):69-78.

23. Nakamura Y. Child abuse and neglect in Japan. Pediatr Int. 2002 Oct;44(5):580-1.

24. Simons RL, Beaman J, Conger RD, Chao W. Childhood experience, conceptions of parenting, and attitudes of spouse as determinants of parental behavior. J Marriage Fam. 1993;55(1):91-106.

25. Egeland B, Jacobvitz D, Papatola K. Intergenerational continuity of abuse. In: Gelles RJ, Lancester JB, editors. Child abuse and neglect: biosocial dimensions. New York: Aldoine di Gruyter; 1987. p. 225-76.

26. Herrenkohl EC, Herrenkohl RC, Toedter LJ. Perspectives on the intergenerational transmission of abuse. In: Finkelhor D, Gelles RJ, Hotaling GT, Straus MA, editors. The dark side of families: current family violence research. Beverly Hills: Sage Publications; 1983. p. 305-16.

27. Straus MA. Ordinary violence, child abuse, and wife-beating: what do they have in common? In: Finkelhor D, Gelles RJ, Hotaling GT, Straus MA, editors. The dark side of families: current family violence research. Beverly Hills: Sage Publications; 1983. p. 213-34.

28. Azar ST. A cognitive behavioral approach to understanding and treating parents who physically abuse their children. In: Wolfe DA, McMahon RJ, Peters RD, editors. Child abuse: new directions in prevention and treatment across the lifespan. Bannf international behavioral science series. Thousand Oaks: Sage Publications; 1997. p. 79-101.

29. Milner JS. Social information processing in high-risk and physically abusive parents. Child Abuse Negl. 2003 Jan;27(1):7-20.

30. Galdston R. Observations on children who have been physically abused and their parents. Am J Psychiatry. 1965 Oct;122(4):440-3.

31. Garbarino J. A preliminary study of some ecological correlates of child abuse: the impact of socioeconomic stress on mothers. Child Dev. 1976 Mar;47(1):178-85.

32. Sattin DB, Miller JK. The ecology of child abuse within a military community. Am J Orthopsychiatry. 1971 Jul;41(4):675-8.

33. Giovannoni JM, Billingsley A. A child neglect among the poor: A study of parental adequacy in families of three ethnic groups. Child Welfare. 1970;49(4):196-204.

34. Thompson MP, Kingree JB, Desai S. Gender differences in long-term health consequences of physical abuse of children: data from a nationally representative survey. Am J Public Health. 2004 Apr;94(4):599-604.

35. Johnson CF. Child maltreatment 2002: recognition, reporting and risk. Pediatr Int. 2002 Oct;44(5):554-60.

36. Mullen PE, Martin JL, Anderson JC, Romans SE, Herbison GP. The longterm impact of the physical, emotional, and sexual abuse of children: a community study. Child Abuse Negl. 1996 Jan;20(1):7-21.

37. Ocampo PDS. Protecting children's right in a developing country. Pediatr Int. 2002;44(5):570-5. 